\title{
The Nature of the Generics in Island, Ledge, and Rock Names of the Maine Coast
}

\author{
DONALD B. SANDS
}

$T_{\mathrm{r}}$

HE GeNerics in THE NAMES OF MAINE's OFfShore Features fall into four groups and the first half of this study deals with them. Presumably other generics can be similarly treated. The second half, and it is hoped that it grows naturally out of the first, concerns the problem of when elements of binomial toponyms can be considered lexical evidence. The names treated are drawn from the twenty-nine Geological Survey sheets of the $15^{\prime}$ series covering the coast of Maine from Calais township to the New Hampshire border. Coast and Geodetic Survey charts as well as The Coast Pilot: Atlantic Coast-Section $A$ are also used, but primarily as checks on the GS sheets, whose yield of names for islands, at least, shows no marked difference from that which can be taken from the two last-mentioned sources. With ledge and rock names, the same cannot be said, since both the CG charts and The Coast Pilot record somewhat more of these than do the GS sheets. Nevertheless, the sampling provided by the GS sheets seems representative enough for present purposes. ${ }^{1}$ Unfortunately, printed sources supply the main body of data and there is the danger, inherent in all such studies, that oral usage may not be mirrored at all times. However,

1 The titles of the topographic sheets with their edition dates and the number of names of offshore features on each follow: Bar Harbor (1942) 48; Bath (1945) 75; Biddeford (1941) 24; Blue Hill (1944) 28; Boothbay (1944) 92; Casco Bay (1916) 58; Castine (1943) 29; Cherryfield (1904) 23; Columbia Falls (1941) 41; Cutler (1918) 4; Deer Isle (1944) 125; Eastport (1943) 40; Freeport (1944) 32; Great Wass Island (1921) 46; Kennebunk (1941) 1; Machias (1941) 38; Matinicus (1906) 28; Monhegan (1906) 103; Mount Desert (1942) 29; Petit Manan (1904) 32; Portland (1916) 4; Robbinston (1931) 2; Rockland (1906) 33; Small Point (1944) 29; Swans Island (1945) 58; Tenants Harbor (1906) 56; Vinalhaven (1944) 107; Waldoboro (1915) 6; and York (1920) 21. 
informants native to the areas of the lower Penobscot and Kennebec Rivers were consulted during the summers of 1957 and 1958 and their responses are noted whenever they seem at variance with printed evidence.

\section{I.}

The total number of names recorded for islands, ledges, and rocks is 1212 , but the figure is a little deceiving in that it represents fewer water-encompassed features than are actually shown. The ones not represented are those situated in individual clusters, each cluster being given a collective name usually distinguished by a pluralized generic. There are ninety-nine of these and hence there must be at least as many more actual islands, ledges, and rocks figured on the sheets. If a collective name covers three, and three would seem to be about average, then the number of water-encompassed areas must be close to 1410 .

Treatment can best begin by clearing away the more basic generics and also those which would seem to be among the more basic but actually are not. There are 904 names with the generic island expressed, of which fifty-six are plural. ${ }^{2}$ The figure implies that the remaining 308 names must show one or the other of the two most common generics - namely, ledge or rock - but only to a degree is the implication correct. One hundred nineteen show the generic ledge, of which thirty are plural, and eighty-nine show the generic rock, of which thirteen are plural. These figures account for all but one hundred names. Reef as a generic appears but once, in Two Bush Reef. Breaker, in the sense "ledge", appears three times; there is one ledge bearing the name Southeast Breaker and two the name South Breaker. The word is native to Maine's toponymy and dialect; it appears apparently in names of similar application elsewhere only in California. ${ }^{3}$ There are seven appearances of the now semi-poetic isle: three with simple attributives, in Deer Isle, High Isle, and Little Deer Isle; three in phrasal combinations, two

2 These, incidentally, are genuine plurals and in no way genitive constructions.

3 A point made by Meredith F. Burrill in his paper "Localized Toponymic Generics," read at the Association of American Geographers in Cincinnati April 2, 1957, a mimeographed copy of which Mr. Burrill kindly supplied. The OED lists a close usage "a break-water (obs)" with one New World citation dated 1661; the $D A$ covers the word with "a reef or bank on which the waves break. ?Obs." with the earliest attestation dated 1722. Toponymically, the term seems far from obsolete. 
English, in Isle of Springs and Isles of Shoals, and one French, in Isle au Haut; and one in preposed and combined position, in Islesboro. Two observations are called for. One is that Maine's offshore pilots refer to small rocky projections in the sea as ledges and not reefs. Informants living in the estuary region of the Penobscot River substantiate this statement, as do the large-scale CG charts for the Penobscot Bay area, whereon additional names using breaker may be found but, with only an isolated exception or two, no further instances of reef appear. The other observation is that isle is present only with names which were given either early in Maine's history or relatively late, the latter being the case with Isle of Springs, which was originally Swett or Sweet Island, so called after a family of that name. ${ }^{4}$ The diminutive islet seems not to appear on the Maine Coast at all, although in the Hydrographic Office publications for the eastern Canadian coast it is not infrequent. ${ }^{5}$ With these disposed of, there are eighty-nine names left.

What follows is not so simple and several curious problems are involved, because, although the remaining names belong to areas that are geographically islands, ledges, and rocks, none of them employs a generic of the kind just treated. With the 1212 names being considered, four distinct categories of generic are evident. The first, the one just treated, is that of the true generic. A second is that of the transferred generic, a category made up of terms which elsewhere are true generics, but in this particular category serve as generics in names of areas that do no fit the lexical sense of the generic used.6 A generic, however, is here considered transferred

4 The US Geographic Board in its Sixth Report (GPO 1933) fixed the name as Sweet Island, but reversed the decision in the "Decision Lists" for July-June 1941; it is now officially Isle of Springs and not Sweet, Sweat's, or Swetts' Island.

5 Sailing Directions HO No. 99 "Nova Scotia" (1939) lists Ball Islet, Basque Islets, Breakfast Islet, and so on for about an average of two islet generics per page for thirty pages of index; a somewhat lower average per index page holds for Sailing Directions HO N. 100 "The Gulf and River of St. Lawrence" (1934), HO No. 76 "Baffin Bay and Davis Strait" (1947), and HO No. 73 "Newfoundland" (1942). Only HO No. 100 shows in its index the French forms ile, iles, and ilot.

- The label transferred generic can undoubtedly be improved, but the phenomenon it names is common. In Maine, for example, Bailey and Chebeague Islands in Cumberland County, Capitol Island in Lincoln County, and Cliff Island in the first ward of Portland are officially and locally both islands and villages. Stowell Rounds discusses a related matter in Names, VI, 2 (June 1958), 124-25, when he cites instances where street appears as the generic in names of small towns. 
only if it appears two or more times in a particular transferred sense, those terms in generic position appearing only once being considered, perhaps somewhat arbitrarily, in a final category, that of the generic by position.

Six different transferred generics appear and they cover eighteen different island names. Haven is one; it appears twice, in North Haven and Vinalhaven. The latter island was named first; its second element was eventually carried over into the name of its immediate northern neighbor; and in these two instances, haven is an equivalent of "island". " Head appears as a transferred generic five times, in Bluff Head, Carrying Place Head, Outerhead, and Squaw Head; neck appears twice, in Stinson Neck and Whitmore Neck; and port also appears twice, in Southport and Westport. The head generics arise from the fact that four belong to islands having promontories or "heads" and that one belongs to an island situated at the head of a carry. The necks appear in names for areas which are geographically islands, but, from the pilot's point of view, necks of the mainland. The ports are peculier in that the areas designated by the names in which they appear are so much a part of the mainland that their island nature is only cartographically apparent.

Two transferred generics remain; they are in the names of low conical islands, one being $k n o b$ and the other $n u b$ with its variants knubble and nubble, here for the sake of convenience considered as one. The former appears three times, twice in the basically tautological Pumpkin Knob and again in Thurlow Knob, while the latter appears four times, in the combinations Conary Nub, Little Knubble, Cutters Nubble, and Jennys Nubble. In Maine, names of conical mainland elevations, especially in the Mount Desert region, often show $k n o b$ and $n u b$ as generics and similarly shaped offshore elevations have borrowed them. ${ }^{8}$

7 Cf. George J. Varney, A Gazetteer of the State of Maine, Boston, B. B. Russell 1881, pp. 400, 553-54. The eighteenth century names were North and South Fox Islands.

8 Although knob in the sense "hill" is now used chiefly in American English (it is attested in its geographic sense as early as 1650 by the $O E D$ ), nub and its byforms knubble and nubble, plus nubbin, which appears as a generic only on the mainland, are frequent in Maine toponyms. The $O E D, D A E, D A, E D D$, and The Century Dictionary of 1911 do not note their toponymic application, nor are any of the forms to be found in A.H. Smith's English Place-Name Elements, Cambridge, Eng., 1956. There may be, moreover, a certain projective connotation in these 
A third category, the second beyond that of the true generic, is the one which substitutes the difinite article for a generic. ${ }^{9}$ The names themselves appear in the singular or the plural, according to whether what is named is made up of one or more than one area. Conceivably, these names could appear with true generics; feasible in oral as well as written usage is the phrase "rowing by Keg Rock," but "rowing by The Keg" shows the definite article in a special function. It indicates to a local pilot a particular water-encompassed area that is a navigationally critical one - one, for example, that he can use as a reference, since in all probability it is situated at the entrance to a channel or at some easily noted distance between one harbor and another. Such areas, then, are distinctive and their distinctiveness is signaled by a special naming process, that which uses the article plus the name of an object the area resembles in shape or the name of an object the area has by folk imagination somehow acquired. In short, the in a given coastal context implies something which island, ledge, or rock would not imply.

In this third category fall fourteen names in the singular - The Ark, The Barrel, The Castle, The Downfall, The Fort, The Hogshead, The Hop, The Hub, The Ladle, The Neck, The Nub, The Nubbin, and The Thrumcap - and thirteen examples in the plural The Brothers (there are three of this name), The Cuckolds, The Goslings, The Graves, The Hypocrites, The Kegs, The Porcupines, The Shivers, The Sisters, The Triangles, and The Twinnies.10 Their origin is generally apparent, distinctive shape being indicated by most. The Hop, however, derives from position; it is, although perhaps not literally, within hopping distance of Long Porcupine Island in Frenchman Bay. The Brothers, The Sisters, and The Twinnies derive from the relatively close grouping of the ledges they name, the last being or having been, according to one informant, locally Twin Tits. The Downfall, The Graves, The Cuckolds, and The Hypocrites belong to a large group of ledges that bear lugubrious names and are of a singularly treacherous nature. The first two probgenerics, since several native informants attest local use of nub and nubbin in the sense "small" or "immature breast."

9 Cf. James B. McMillan, "Observations on American Place-Name Grammar," $A S, \mathrm{XXIV}, 4$ (Dec. 1949), $243 \mathrm{ff}$.

10 Three single element names appear on the GS sheets without the article Sisters, Spectacles, and Thrumcap. They are, in view of other names like them, inconsistent and are probably oversights. 
ably derive from historical incident; the last are products of folk imagination. No explanation of The Cuckolds is really conclusive. Their low flat surface precludes the possibility that horn-like similarity suggested the name and their outline is not at all horn shaped.11 Even though these ledges - they lie just off Cape Newagen - are frequented by various species of shore bird, W. L. McAtee, the authority on ornithological folk names, cannot identify any bird name that would be pertinent. ${ }^{12}$ Horace Beck notes their particularly hazardous location and adds that they have caused "many a homing mariner... [to be] deluded."13 Cuckolds, however, do not delude and it is probably their strikingly forsaken nature suggestive of the cuckold himself that has made the name stick. With The Hypocrites, development is historically clear. No one knows the original name of these two uninhabited islets situated at the eastern entrance to Fisherman Passage by Linekin Neck. In 1674 the name Hyppocras Island was applied to what is now Fisherman Island; the specific derived by folk etymology from an Indian name Epituse, which did not mean anything to the early white settlers while hyppocras did, namely "a spiced wine."14 When the new name Fisherman Island was applied to Hyppocras, the latter's name was transferred to the tiny islets some three-quarters of a mile due east and here it was again altered by folk-etymology, this time to The Hypocrites, the wine name being by the end of the eighteenth century chiefly a learned item. ${ }^{15}$

Forty-one names remain. These also are printed on the GS sheets without island, ledge, or rock or their dialect synonyms and wellinformed native residents of Islesboro affirm that the dozen generic-

11 Maine apparently offers no other toponymic use of cuckold; but Newfoundland has two Cuckold Coves, two Cuckold Heads, a Cuckold Rocks, and a Cuckolds Point, according the HO No. 73 "Newfoundland," mentioned in footnote 5.

12 Letter dated November 24, 1958.

13 The Folklore of Maine, Philadelphia, J. B. Lippincott, 1957, p. 13.

14 Beverage names abound in coastal Maine; there are, among others, Dram Island, Grog Island, Grog Ledge, Rum Key and Rum Island; but coves and inlets seem to be particularly favored with beverage specifics with rum being the most frequent.

15 Fanny H. Eckstorm, "Indian Place-Names of the Penobscot Valley and the Maine Coast," The Maine Bulletin, XLIV, 4 (Orono, Me., 1941), 120. Mrs. Eckstorm was unable to identify the name Epituse, but assumes (p. 121) that it may have "meant that the island lay between the two passages into Boothbay." Cf. Francis B. Greene, History of Boothbay, Portland, Loring, Short, and Harmon, 1906, pp. 19-21. 
less names on the charts of East and West Penobscot Bays are also genericless in oral use. Here, three features common to all generics should be noted - frequency, lexical sense, and position. ${ }^{16}$ Frequency has already been touched on - the fact that a term should appear several times in different toponymic combinations applied to similar geographic features before it can be classed a generic. A geographic sense is a requisite. Bull, although it appears a halfdozen times in names of ledges and rocks in generic position (Roaring Bull and White Bull, for example), is not a generic, since no sense "ledge" can be attested outside of toponymics for the term bull. Position is a third feature, since a generic is usually the second element in a binomial, although occasionally in some other position, as in Isles of Shoals, where the generic heads a phrase, and it is position that can serve as the basis for the final category, one made up of binomials containing terms which appear in one of the two or three possible generic positions, but which do not have a lexical sense appropriate to the geographic feature named.

There are thirty examples in the singular - Big Pot, Blackhorse, Brown Cow (there are two of this name), Devils Back, Devils Elbow, Devils Limb, East Barge, Eastern Ear, Fiddle Head, Goosenest, High Sheriff, Junk of Pork (there are two of this name), Niggerhead, No Mans Land, Pound of Tea, Rabbits Ear, Roaring Bull, Rum Key, Saddleback, Thunder Hole, Thrumcap Monument, Torrey Castle, West Barge, Western Ear, Whaleback (there are two of this name), White Bull, and Whitehorse - and four in the plural - Northern Triangles, Southern Triangles, Stepping Stones, and Sugar Loaves. Here also might be placed Jordans Delight, Kemps Folly, and Popes Folly, although there is some evidence that delight and folly were once true generics. ${ }^{17}$

Most of these names are similar to the ones in the preceding category in that they apply to relatively small water-encompassed areas which are both navigational aids and hazards; and the basis of naming just discussed also applies here in most cases. It can be noted parenthetically that in neither of the two categories does a patronym

16 Cf. Meredith F. Burrill, "Toponymic Generics I," Names IV, 3 (Sept. 1956), 129, where generics are defined as "terms for physical features used in geographic names."

17 George R. Stewart, Names on the Land, Boston, Houghton Mifflin, 1958, p. 460, discusses folly; delight with the possible generic sense "resort" is attested by some dozen instances collected by the writer. 
or eponym appear, both categories employing terms of high lexical frequency and, for the most part, of concrete lexical signification. Some doubt can be raised as to the orthography of Goosenest, Niggerhead, Saddleback, Whaleback, and Whitehorse. Edwin G. Gudde notes that Sugarloaf Hill appears without the generic usually as Sugar Loaf, ${ }^{18}$ and presumably the same orthographic convention should apply here (as it does, for example, in the GS printing of Fiddle Head), because it is a visual suggestion that the two elements have the level stress which is given, certainly in the lower Penobscot area, to the majority of island, ledge, and rock names made up of one specific followed by a true generic.

The names that remain fall, for one reason or another, outside the foregoing classification. Arrowsic and Georgetown, which are two large areas of land off the lower left bank of the Kennebec seem never to have had generics attached to their names; but no one on Route 127 would be likely to know he were on island territory unless told; bridges and roads obliterate their island nature. Sow and Pigs is printed by a cluster of ledges just northeast of Bustins Island on the Freeport quadrangle; it is the only name so compounded in the whole group. One might expect more of the type (as Horse and Mare and Pot and Ladle) and undoubtedly in oral use in certain foreshore areas many more do exist, since two rocks side by side would seem to call forth such names from rural coastal residents. The Black Rocks appears on the Boothbay quadrangle beside a group of dry rocks at the western approach to Sheepscot Bay. The form is unique. Whether it is an error or an attempt to represent local usage is not certain; but its very uniqueness, both in form and in the location of the rocks it names (they are well out beyond similar obstructions), seems to make the latter possibility feasible, since, as already noted, the article apparently attaches itself readily to distinctive navigational references.

\section{II}

And now a word about thrumcap as a means of illustrating the iexical difficulties presented by terms which may or may not be archaic dialect fossilized in toponyms. ${ }^{19}$ None of the informants

18 "Sugarloaf," Names, IV, 4 (Dec. 1956), 241.

19 Thrumcap, perhaps only by association, is treated at length as a generic by Meredith F. Burrill, "Toponymic Generics II," Names, IV, 4 (Dec. 1956), 231-32; 
mentioned in the first paragraph could suggest the original meaning of the word, although one or two (the Postmaster of Islesboro, for example) wondered whether it might be an incorrect or archaic spelling of thumbcap. A Canadian publication, noting the shoal Thrumcap at the entrance to Halifax Harbor, explains it as being "probably from the 'thrumming' noise of the surf on the 'cape'." But -cap as a bound form of cape would be difficult to find in English elsewhere, although thrum in its noise sense "drum" does probably lie behind Thrum Point and Big and Little Thrum Islets on the Nova Scotia coast. Actually it is most likely that the term is the same as thrumcap, "a knitted cap once worn by sailors," first attested by the OED in $1624 .{ }^{21}$ But only one dictionary, The Century of 1911, notes its toponymic use; yet with a definition - "a ragged rocky headland swept by the sea. Also thrum-cap. (Nova Scotis)" which is misleading on two counts. First, there are apparently no instances of thrumcap used in names which do not refer to small islands or, exceptionally, shoals; and second, there are a good number of thrumcap combinations outside of Nova Scotia - namely, around the island of Newfoundland, in the Gulf of St. Lawrence, and down the upper coast of Maine. ${ }^{22}$

As for its functions, thrumcap appears most frequently as a specific - chiefly with a true generic, as in Thrumcap Island (Maine has three of this name); but also with the generic by position, as in Thrumcap Monument; with the definite article as generic, as in The Thrumcap; and finally, with no generic at all, as in Thrumcap, as though the name were similar to Big Pot and Blackhorse, although inappropriately, because both of these names are given level stress locally while thrumcap is given the accentuation of oar lock his conclusion that the word "never did have practical significance," however, is the one arrived at here.

20 Fourteenth Report of the Geographic Board of Canada (1916), Ottawa, 1917, p. 267.

21 The view held by The Sixth Report of the US Geographic Board (GPO 1933) in its explanation of The Thrumcap, the name of an island some three and a half miles southeast of the town of Bar Harbor. The Report cautions against use of the forms thrumbcap and thumcap and types the islands so named as "bare ... [with] a tuft of pines or spruce at ... [the] peak."

22 Nova Scotia does, however, show highest frequency. The index to the Sailing Directions for Nova Scotia (mentioned in footnote 5) lists fourteen thrumcap names, while the index to The Coast Pilot: Atlantic Coast-Section $A$ (St. Croix River to Cape Cod) lists only seven. 
and headland. No instance of thrumcap in typical generic position that is, as second element in a binomial - appears on the Maine Coast, although Nova Scotia has two, in Big Thrumcap and Little Thrumcap. These aspects known, one can ask what sort of a term is thrumcap. Should it be considered a lexical item and defined as "a small, conical island often with a tuft of trees in the center?" There are sufficient offshore features bearing the term thrumcap as a specific to warrant such a definition on the basis of frequency. Or should such a sense, because it is toponymically but not otherwise attested be relegated to toponymy only? The latter alternative seems the sounder, and simply because generic position is usually the lexical one while specific position, the one thrumcap almost always occupies, is usually the metaphoric. Returning, then, to the definition in The Century Dictionary, one can find it misleading on yet a third count; it is entered without benefit of a guide phrase restricting the sense given to toponymy.

The toponymic frequency of thrumcap is due to the ubiquity of a type of headgear among sailors of the Maine and Canadian coasts a century and a half ago and the presence of certain islands resembling it in shape and appearance. It is metaphorical, but unlike some other generics which also at first must have been metaphorical and similarly restricted to specific position, thrumcap seems never to have jumped the gap from specific to generic. Here perhaps is a rule of thumb (the pun is incidental): frequency in generic position can be balanced against frequency in specific position. If appearances in the former predominate, it is likely that an unrecorded term present in toponymic combinations may also be a lexical item for a geographic feature. If specific position predominates, as it does with thrumcap, then the term probably never achieved status as the name for a geographic feature. Arbitrary and obvious as the idea may seem, the large number of specifics and generics not lexically recorded that have been collected by the writer from maps, charts, and township records of the coastal areas of New England indicates that some such working distinction is necessary.

Boston College

Chestnut Hill 67

Massachusetts 